Jurnal Ilmu Ilmu Agribisnis: Journal of Agribusiness Science, 9(1), Februari 2021

\title{
ANALISIS RISIKO USAHA BUDIDAYA IKAN LELE DUMBO DI KECAMATAN KOTA GAJAH KABUPATEN LAMPUNG TENGAH
}

(Business Risk Analysis of Lele Fish Culture in Kota Gajah Subdistrict Central Lampung Regency)

Neni Marlina, Ktut Murniati, Eka Kasymir

Jurusan Agribisnis, Fakultas Pertanian, Universitas Lampung, Jl. Prof. Dr. Soemantri Brodjonegoro No. 1

Bandar Lampung 35145, e-mail: ktut.murniati@fp.unila.ac.id

\begin{abstract}
This research aims to determine the level of risk and behavior faced by farmers in dumbo catfish farming. This research was a survey conducted in Kota Gajah Subdistrict of Central Lampung Regency in AugustSeptember 2018. Respondents are 44 dumbo catfish farmers members of the Fish Cultivation Group (pokdakan) taken using simple random sampling. The results of this research showed that the dumbo catfish farming in Kota Gajah Subdistrict of Central Lampung Regency has the CV value price risk of 0.04 and the lower limit $(L)$ of IDR15,320. The CV value less than 0.50 means that farmers risk suffered losses due to changes in low classified price. CV value of production risk is 0.04 and the lower limit $(L)$ is $2,449.33 \mathrm{~kg}$. The $C V$ value less than 0.50 means that farmers risk experiencing losses due to changes in production relatively low. Based on the analysis that was done with the quadratic utility approach shows that dumbo catfish farmers in Kota Gajah Subdistrict are 41 farmers behave neutrally and 3 farmers behave boldly in facing the risk of catfish farming.
\end{abstract}

Key words: behavior, dumbo catfish, farmers, risk

\section{PENDAHULUAN}

Provinsi Lampung merupakan salah satu daerah yang memiliki sektor perikanan yang cukup dominan baik itu dari perikanan tangkap maupun perikanan budidaya. Komoditas ikan lele merupakan jenis ikan yang paling dominan dibudidayakan di Kabupaten Lampung Tengah. Usaha budidaya yang dilakukan di Kabupaten Lampung Tengah meliputi pembenihan hingga pembesaran ikan air tawar. Ikan air tawar yang sering dibudidayakan oleh masyarakat Provinsi Lampung diantaranya ikan nila, lele, gurame, dan ikan patin. Komoditas ikan yang paling banyak dibudidayakan oleh masyarakat di Provinsi Lampung yaitu ikan lele dumbo.

Komoditas ikan dengan produksi tertinggi di Provinsi Lampung adalah komoditas ikan lele dibandingkan produksi jenis ikan lainnya, dimana produksi ikan lele pada tahun 2018 mencapai 25.744,60 ton, sedangkan ikan gurame dan ikan nila menempati urutan kedua dan ketiga dengan produksinya sebesar $8.147,64$ ton dan ikan nila sebesar 7.983,19 ton (Direktorat Jenderal Perikanan Budidaya 2019).

Ikan lele dumbo merupakan jenis ikan konsumsi air tawar dengan kulitnya yang licin dan memiliki sungut. Budidaya ikan lele salah satu jenis usaha yang saat ini masih digemari masyarakat. Hal ini disebabkan karena budidaya ikan lele dumbo tidak memerlukan waktu yang lama untuk proses pemanenan, proses perawatannya mudah, dan biaya yang dibutuhkan relatif ringan (Darseno 2013).

Kabupaten Lampung Tengah merupakan salah satu kabupaten yang mempunyai jumlah produksi ikan lele yang cukup tinggi di Provinsi Lampung. Menurut Dinas Kelautan dan Perikanan Provinsi Lampung (2019), produksi ikan lele dumbo di Kabupaten Lampung Tengah berfluktuatif dari tahun 2014 hingga tahun 2018. Namun, pada tahun 2016 terjadi peningkatan produksi yang cukup drastis dibandingkan tahun sebelumnya. Kabupaten Lampung Tengah merupakan daerah terbesar sebagai produsen ikan lele dumbo di Provinsi Lampung dengan rata-rata memproduksi ikan lele sebesar $6.832,85$ ton per tahunnya, disusul oleh Kabupaten Pringsewu dengan rata-rata produksi sebesar $3.567,61$ ton per tahunnya, dan Kabupaten Lampung Selatan dengan produksi sebesar $2.587,83$ ton per tahunnya.

Menurut Dinas Peternakan dan Perikanan Kabupaten Lampung Tengah (2019), pada tahun 2018 produksi ikan lele dumbo di Kecamatan Kota Gajah sebesar 365 ton. Kecamatan Kota Gajah menempati urutan pertama dalam produksi ikan 
lele dumbo di Kabupaten Lampung Tengah, diikuti oleh Kecamatan Punggur dengan produksi 360 ton dan Seputih Raman dengan produksi 300 ton pada tahun yang sama.

Produksi budidaya ikan lele dumbo di Kecamatan Kota Gajah berfluktuasi setiap tahunnya. Adanya penurunan dan fluktuasi produksi ikan lele tentu akan berpengaruh terhadap keberlangsungan usaha budidaya ikan lele dumbo di Kecamatan Kota Gajah Kabupaten Lampung Tengah. Berdasarkan uraian tersebut, perlu adanya kajian analisis risiko dan perilaku petani dalam menghadapi risiko pada usaha budidaya ikan lele dumbo di Kecamatan Kota Gajah Kabupaten Lampung Tengah. Penelitian ini bertujuan untuk menganalisis risiko usaha budidaya ikan lele dumbo dan menganalisis perilaku petani dalam menghadapi risiko usaha budidaya ikan lele di Kecamatan Kota Gajah Kabupaten Lampung Tengah.

\section{METODE PENELITIAN}

Penelitian dilakukan di Kecamatan Kota Gajah Kabupaten Lampung Tengah dengan menggunakan metode penelitian survei. Pengambilan data dilakukan di Desa Kota Gajah dan Kota Gajah Timur dengan pertimbangan bahwa desa tersebut merupakan sentra budidaya ikan lele. Data yang digunakan adalah data primer dan data sekunder. Populasi pada penelitian ini adalah petani pembudidaya ikan lele yang ada di Kecamatan Kota Gajah. Populasi petani pembudidaya ikan lele adalah 238 petani, dari populasi tersebut ditentukan jumlah sampel penelitian yang mengacu pada Issac dan Michael dalam Sugiarto D, S Sunaryanto, dan DS Oetomo (2003) sebagai berikut:

$\mathrm{n}=\frac{\mathrm{N} Z^{2} \mathrm{~S}^{2}}{\mathrm{Nd^{2 } + Z ^ { 2 } \mathrm { S } ^ { 2 }}}$

Keterangan:

$\mathrm{n} \quad=$ Jumlah sampel

$\mathrm{N} \quad=$ Jumlah populasi

$S^{2} \quad=$ Variasi sampel $(5$ persen $=0,05)$

$\mathrm{Z} \quad=$ Distribusi $\mathrm{Z}(90$ persen $=1,64)$

$\mathrm{d}=$ Simpangan baku $(5$ persen $=0,05)$

Berdasarkan perhitungan dengan menggunakan rumus tersebut, maka jumlah sampel adalah :

$\mathrm{n}=\frac{238 \times(1,64)^{2} \times(0,05)}{325 \times(0,05)^{2}+(1,645)^{2}(0,05)}=44$
Berdasarkan perhitungan yang dilakukan diperoleh petani di daerah penelitian, yaitu sebanyak 44 petani ikan lele di Kecamatan Kota Gajah yang dipilih secara acak (simple random sampling). Responden tersebut diperoleh dari 3 kelompok budidaya ikan/POKDAKAN (Mina Karya Luhur, Karya Bakti Mina, dan Usaha Maju Bersama) yang berada di Kecamatan Kota Gajah. Waktu pengambilan data dilakukan pada bulan AgustusSeptember 2018.

Metode yang digunakan untuk menjawab tujuan pertama adalah menggunakan analisis risiko. Tingkat risiko usahatani budidaya ikan lele ditentukan berdasarkan nilai Koefisien Variasi (CV). Penelitian ini sejalan dengan penelitian Heriani, Zakaria dan Soelaiman (2013) tentang risiko usahatani tomat yang menentukan tingkat risiko berdasarkan nilai CV. Koefisien variasi merupakan perbandingan risiko yang harus dihadapi petani dengan jumlah pendapatan ataupun produksi yang akan diperoleh dengan hasil dan sejumlah modal yang dikeluarkan dalam proses produksinya. Hubungan ini biasanya diukur dengan koefisien variasi dan batas bawah keuntungan/pendapatan (L). Rumus koefisien variasi adalah sebagai berikut:

$\mathrm{CV}=\frac{\mathrm{V}}{\bar{\pi}}$

Keterangan :

$\mathrm{CV}=$ Koefisien variasi

$\mathrm{V}=$ Simpangan baku

$\pi=$ Keuntungan rata-rata

Rumus batas bawah keuntungan adalah sebagai berikut:

$\mathrm{L}=\mathrm{E}-2 \mathrm{~V}$

Keterangan:

$\mathrm{L}=$ Batas bawah keuntungan

$\mathrm{V}=$ Simpangan baku

$\mathrm{E} \quad=$ Rata-rata pendapatan/produksi

Pada analisis risiko produksi, nilai batas bawah menunjukkan nilai produksi terendah yang mungkin diterima oleh petani. Apabila nilai batas bawah produksi ini sama dengan atau lebih dari nol, maka petani tidak akan pernah mengalami kerugian. Sebaliknya, jika nilai batas bawah produksi kurang dari nol dapat disimpulkan bahwa dalam setiap proses produksi ada peluang kerugian yang akan diderita oleh petani. 
Apabila nilai $\mathrm{CV}>0,50$ maka nilai $\mathrm{L}<0$, begitu pula jika nilai $\mathrm{CV} \leq 0,50$ maka nilai $\mathrm{L} \geq 0$. Hal ini menunjukkan bahwa apabila $\mathrm{CV}>0,50$ maka risiko produksi pada usaha budidaya ikan lele yang ditanggung petani semakin besar dengan menanggung kerugian sebesar L, sedangkan nilai $\mathrm{CV} \leq 0,50$ maka petani akan selalu untung atau impas dengan produksi sebesar L.

Analisis risiko harga, nilai batas bawah harga menunjukkan jumlah harga terendah yang mungkin diterima oleh petani. Apabila nilai CV $>$ 0,50 maka nilai $\mathrm{L}<0$, begitu pula jika nilai $\mathrm{CV} \leq$ 0,50 maka nilai $\mathrm{L} \geq 0$. Hal ini menunjukkan bahwa apabila $\mathrm{CV}>0,50$ maka risiko harga usaha budidaya ikan lele yang ditanggung petani semakin besar dengan menanggung kerugian sebesar L, sedangkan nilai $\mathrm{CV} \leq 0,50$ maka petani akan selalu untung atau impas dengan harga sebesar $\mathrm{L}$.

Metode yang digunakan untuk menjawab tujuan kedua adalah menggunakan analisis perilaku petani dalam menghadapi risiko. Perilaku petani dalam menghadapi risiko dapat diketahui dengan analisis menggunakan analisis fungsi utilitas.

Model fungsi utilitas dapat dirumuskan dalam bentuk polinominal atau kuadratik. Bentuk kuadratik telah digunakan di Indonesia oleh beberapa penulis terdahulu menurut Barry dalam Soekartawi, Rusmiadi, dan E Damaijati (1993), dengan persamaannya sebagai berikut:

$\mathrm{U}=\tau 1+\tau 2 \mathrm{M}+\tau 3 \mathrm{M} 2$

Keterangan:

$\mathrm{U}=$ Utilitas bagi pendapatan yang diharapkan

$\tau 1=$ Intersep

$\tau 2=$ Koefisien pendapatan indiferen

$\tau 3=$ Koefisien risiko petani

$\mathrm{M}=$ Pendapatan yang diharapkan pada titik keseimbangan (nilai rupiah dari certainty equivalent (CE)

Dimana nilai $\tau 3$ hasil regresi menunjukkan sikap petani terhadap risiko, yaitu :

$\tau 3=0:$ Netral terhadap risiko

$\tau 3<0$ : Enggan terhadap risiko

$\tau 3>0$ : Berani terhadap risiko

Pembentukan fungsi utilitas dilakukan dengan menghubungkan skala utilitas, sehingga setiap petani akan memiliki certainly equivalent (CE) yang berbeda. Certainly equivalent (CE) merupakan nilai keseimbangan antara kondisi yang tidak pasti dengan kondisi yang pasti.

\section{HASIL DAN PEMBAHASAN}

Hasil penelitian menunjukkan bahwa sebesar 97,72 persen petani berada pada kelompok umur 15-64 tahun dan 52,28 persen petani pernah menempuh pendidikan formal pada tingkat sekolah menengah (SMA). Pengalaman petani dalam berusahatani budidaya ikan lele cukup beragam, sebanyak 61,36 persen mereka telah berpengalaman 5-10 tahun, sedangkan sisanya lebih dari 10 tahun. Sebagian besar petani budidaya ikan lele memiliki jumlah tanggungan keluarga antara 3-5 jiwa (79,54\%). Kepemilikan lahan kolam petani budidaya ikan lele beragam dengan luas lahan terbesar 72,73 persen petani memiliki kolam kurang dari $500 \mathrm{~m}^{2}$. Pendapatan petani di luar kegiatan usahatani diperoleh dari pekerjaan sampingan yaitu buruh pabrik, wiraswasta, dan pedagang (warung).

\section{Usahatani Ikan Lele}

Pada usahatani budidaya ikan lele, jenis kolam yang dipakai di Kecamatan Kota Gajah adalah kolam tanah. Petani pembudidaya ikan lele beranggapan bahwa penggunaan kolam tanah lebih efektif dan mudah jika dibandingkan dengan kolam semen dan menggunakan modal lebih sedikit jika dibandingkan dengan pembuatan kolam semen. Pada penelitian ini, budidaya ikan lele yang dilakukan adalah budidaya pembesaran ikan lele.

Awal budidaya ikan lele adalah persiapan kolam. Pada jenis kolam tanah yang digunakan petani ikan lele diperlukan kedalaman 80-100 cm dalam pembudidayaan ikan lele. Setelah persiapan kolam selesai, kemudian dilakukan penaburan kapur atau dolomit untuk menyeimbangkan kadar keasaman kolam, pemberian kapur 200-300 kg per kolam tergantung pada luasan lahan kolam dan derajat keasaman kolam, kemudian lakukan pengolahan kembali agar kapur pertanian ini tercampur rata pada tanah kolam.

Setelah kolam diberi kapur, isi dengan air sampai batas $30-40 \mathrm{~cm}$. Biarkan kolam tersinari matahari selama satu minggu, dengan kedalaman seperti itu sinar matahari masih bisa tembus hingga dasar kolam dan memungkinkan biota dasar kolam seperti fitoplankton tumbuh dengan baik. Air kolam yang sudah ditumbuhi fitoplankton berwarna kehijauan.

Penebaran benih ikan lele dilakukan setelah persiapan kolam selesai. Pada budidaya ikan lele, jenis benih ikan lele dumbo yang didapat dari 
petani yang melakukan pembenihan ikan. Kepadatan benih yang ditebar akan menentukan produksi yang akan dihasilkan. Namun, apabila semakin tinggi tingkat kepadatan benih ikan lele dumbo, maka tingkat risiko kematian juga akan meningkat. Benih ikan lele dumbo yang ditebar di Kecamatan Kota Gajah berukuran 5-7 cm yang berumur sekitar tiga minggu. Benih ikan lele dumbo dibeli dari petani ikan lele yang melakukan proses pendederan ikan/pembenihan. Harga yang ditawarkan per satuan benih Rp100,00/ekor. Benih ikan lele dumbo dijual dengan menggunakan gelas, harga benih ikan lele dumbo per gelasnya Rp13.000,00-Rp15.000,00 dengan isi per gelas 100 benih ikan lele dumbo.

Sebelum benih ditebar, lakukan penyesuaian iklim terlebih dahulu. Caranya, masukkan benih ikan lele dengan wadahnya (ember) ke dalam kolam. Biarkan selama 15 menit, agar terjadi penyesuaian suhu tempat benih dengan suhu kolam sebagai lingkungan barunya. Miringkan wadah dan biarkan benih keluar dengan sendirinya. Metode ini bermanfaat mencegah stres pada benih ikan lele.

Pada pengaturan air, pengisian air dilakukan secara berkala. Pada awal benih ikan baru ditebar, ketinggian air yang diperlukan hanya setengah dari kedalam kolam yaitu $40-50 \mathrm{~cm}$. Pengisian air dilakukan secara berkala seiring dengan perkembangan/pertumbuhan benih ikan lele. Air yang digunakan untuk kegiatan budidaya ikan lele didapatkan dari pompa air dan tampungan air yang sudah dipersiapkan oleh petani ikan lele. Musim kemarau tidak menjadi kendala dalam membudidayakan ikan lele, karena kegiatan budidaya ikan lele tidak memerlukan air yang banyak, sehingga tempat penampungan air yang digunakan untuk kegiatan budidaya menjadi salah satu solusi bagi petani ikan lele yang mengalami kesulitan air.

Tabel 1. Fluktuasi rata-rata harga dan produksi ikan lele 5 musim budidaya terakhir di Kecamatan Kota Gajah Kabupaten Lampung Tengah

\begin{tabular}{ccc}
\hline $\begin{array}{c}\text { Musim } \\
\text { Budidaya }\end{array}$ & $\begin{array}{c}\text { Risiko Harga } \\
(\mathrm{Rp})\end{array}$ & $\begin{array}{c}\text { Risiko } \\
\text { Produksi }(\mathrm{Kg})\end{array}$ \\
\hline 1 & $15.580,00$ & $2.489,00$ \\
2 & $15.670,00$ & $2.466,00$ \\
3 & $14.899,00$ & $2.360,00$ \\
4 & $15.227,00$ & $2.487,00$ \\
5 & $15.224,00$ & $2.444,00$ \\
\hline
\end{tabular}

Pemberian pakan pada ikan lele dumbo lebih intensif, petani ikan lele memberikan pakan 3-4 kali dalam sehari. Ikan lele tergolong hewan kanibal artinya pemakan sesama. Oleh karena itu, petani ikan memberikan pakan ikan lebih intensif untuk menghindari ikan yang saling memakan sesamanya. Cara pemberian pakan untuk ikan lele yaitu dengan ditebar langsung ke dalam kolam dan usahakan merata supaya semua ikan mendapatkan pakan yang cukup. Usaha budidaya ikan lele pada tahap pengendalian hama penyakit dilakukan dengan pemberian obat-obatan. Jenis obat yang digunakan untuk petani ikan lele yaitu perasan daun papaya ditambah air dan dicampur dengan vitamin c (sanbe). Pemberian daun papaya adalah salah satu alternatif obat yang diberikan lewat penyuluhan yang pernah dilakukan terhadap petani ikan. Hal tersebut dirasa karena perasan daun pepaya cukup ampuh dalam mengurangi tingkat stres dan untuk mensterilkan air kolam dari penyakit.

Pemanenan ikan lele biasanya setelah mencapai ukuran 8-10 ekor per kg. Ukuran sebesar itu dapat dicapai dalam waktu kurang lebih 3 bulan. Kegiatan panen dilakukan secara manual oleh petani menggunakan jaring dengan dibantu oleh pekerja, kemudian diangkut dan dijual ke tengkulak yang datang langsung ke petani ikan lele. Pada saat ikan lele dipanen, lakukan penyortiran untuk memisahkan ikan lele berdasarkan ukurannya sesuai permintaan pasar. Pemisahan ukuran berdampak pada harga.

\section{Risiko Usaha Budidaya Ikan Lele}

Penilaian risiko yang dilakukan yaitu berupa risiko produksi dan risiko harga. Tingkat risiko dihitung selama 5 musim $(\mathrm{m}-1, \mathrm{~m}-2, \mathrm{~m}-3, \mathrm{~m}-4, \mathrm{~m}-5)$ budidaya terakhir yang didapat dari hasil wawancara dengan petani ikan lele di Kecamatan Kota Gajah mengenai produksi dan harga ikan lele pada musim budidaya sebelumnya. Produksi dan harga ikan lele 5 musim budidaya terakhir di peroleh dari bulan sebelum dilakukan penelitian yaitu pada bulan Januari 2017- Juli 2018. Tabel 1 menunjukan fluktuasi rata-rata harga dan produksi ikan lele 5 musim budidaya terakhir di Kecamatan Kota Gajah Kabupaten Lampung Tengah. Harga rata-rata (E) yang diterima petani dalam usahatani budidaya ikan lele sebesar Rp15.320,00/kg.

Nilai simpangan baku (V) yaitu 423.931 dan koefisien variasi $(\mathrm{CV})$ yaitu sebesar 0,04 . Batas bawah (L) harga ikan lele yaitu Rp14.109,00. Nilai CV kurang dari 0,50 berarti risiko petani 
mengalami kerugian akibat perubahan harga rendah.

Produksi rata-rata (E) yang diterima petani dalam usahatani budidaya ikan lele adalah sebesar $2.499,33 \mathrm{~kg}$. Nilai simpangan baku (V) yaitu 27.308,12 dan koefisien variasi (CV) yaitu sebesar 0,04. Batas bawah (L) produksi ikan lele yaitu $2.310,09 \mathrm{~kg}$. Nilai CV kurang dari 0,50 berarti risiko petani mengalami kerugian akibat perubahan harga rendah. Nilai batas bawah produksi 2.310,09 $\mathrm{kg}$ dapat diartikan bahwa harga ikan lele terendah yang mungkin diterima petani adalah sebesar $2.309,00 \mathrm{~kg}$.

\section{Perilaku Petani Terhadap Risiko}

Perilaku petani terhadap risiko dianalisis dengan menggunakan Teori Bernoulli Neuman Morgenstern (Soekartawi et al 1993). Teori ini menyebutkan dalam menganalisis perilaku petani dilakukan perhitungan terhadap CE (Certainly Equivalent). CE dapat diketahui apabila tingkat harga optimistik (THO) telah ditentukan yaitu perkiraan harga tertinggi yang diperoleh oleh petani dan tingkat harga pesimistik (THP) yang merupakan harga terendah yang diterima petani yaitu nol. Harga ikan lele saat observasi merupakan tingkat harga netral (THN) dimana digunakan untuk mengetahui tingkat harga optimistik (THO). Masing-masing petani pembudidaya ikan lele memiliki nilai $\mathrm{CE}$ yang berbeda-beda. Nilai CE (Certainly Equivalent) ditentukan menggunakan skema penentuan certainly equivalen (CE) yang telah dijelaskan oleh Soekartawi (1993), dimana tingkat harga keseimbangan dapat diketahui mulai dari tahap 1 sampai tahap 7. Perkalian antara tingkat harga keseimbangan dan produksi ikan lele (per hektar) akan memperoleh penerimaan dan pendapatan setelah dikurang dengan biaya tunai per hektar masing-masing responden pada masing-masing tingkat harga keseimbangan.

Nilai-nilai CE (Certainly Equivalent) yang telah diperoleh dengan skala utilitasnya, kemudian diuji dengan regresi non linier kuadratik. Harga jual ikan lele dan jumlah produksi ikan lele per hektar akan diregresi dan menghasilkan menghasilkan nilai koefisien risiko (M2) dan nilai signifikansi koefisien risiko (M2). Koefisien risiko yang bernilai positif dan signifikan berarti petani berani dalam menghadapi risiko, koefisien risiko bernilai negatif dan signifikan berarti bahwa petani enggan dalam menghadapi risiko dan nilai koefisien risiko positif, negatif atau bernilai nol, tetapi tidak signifikan berarti perilaku petani netral dalam menghadapi risiko.

Berdasarkan analisis yang telah dilakukan dengan pendekatan utilitas kuadratik, bahwa 93 persen petani pembudidaya ikan lele di Kecamatan Kota Gajah netral dalam menghadapi risiko usahatani. Ada tiga responden yang berani menghadapi risiko, karena tingkat penyerapan pasar terhadap ikan lele cukup baik di kalangan petani dan tidak satupun petani enggan dalam menghadapi risiko usahatani.

Menurut Kadarsan (1995), netral dalam menghadapi risiko merupakan perilaku petani dimana petani mengambil keputusan dengan bersikap ragu-ragu atau tidak tegas dalam memilih tindakan pada keadaan yang mengandung risiko dalam usahatani. Dengan berperilaku netral artinya petani tidak terlalu memikirkan risiko yang ada, petani akan tetap melakukan usahataninya seperti biasa tanpa ada pengurangan ataupun penambahan faktor produksi yang digunakan.

Hal ini sejalan dengan penelitian Saputra, Lestari dan Nugraha (2017) tentang perilaku petani dalam menghadapi risiko usahatani jagung. Mayoritas petani jagung berperilaku netral dalam menghadapi risiko dan hanya 1,72 persen berperilaku enggan dalam menghadapi risiko, serta tidak dijumpai petani yang berani dalam menghadapi risiko. Tidak jauh berbeda dengan penelitian Aini, Prasmatiwi dan Sayekti (2015), tentang usahatani kubis pada lahan kering sebesar 93,18 persen petani berperilaku netral dan 6,82 persen berperilaku enggan terhadap risiko, sedangkan pada lahan sawah tadah hujan sebesar 41,94 persen petani berperilaku netral dan 58,06 persen petani berperilaku enggan terhadap risiko.

\section{KESIMPULAN DAN SARAN}

Risiko produksi dan risiko harga pada usahatani budidaya ikan lele di Kecamatan Kota Gajah tergolong rendah dilihat dari nilai $\mathrm{CV}<0,50$ dengan $\mathrm{L}>1$. Nilai koefisien variasi $(\mathrm{CV})$ produksi sebesar 0,04 dengan batas bawah (L) produksi sebesar $2.449,33 \mathrm{~kg}$ per hektar, sedangkan koefisien variasi (CV) harga sebesar 0,04 dengan batas bawah (L) harga ikan lele yaitu Rp15.320,00/kg. Petani ikan lele di Kecamatan Kota Gajah bersifat netral terhadap risiko usahatani sebanyak 41 petani (93\%) artinya petani tidak berani dan tidak pula enggan terhadap risiko usahatani budidaya ikan lele. Tiga petani ikan lele lainnya berani menghadapi risiko. 


\section{DAFTAR PUSTAKA}

Aini HN, Prasmatiwi FE dan Sayekti WD. 2015. Analisis pendapatan dan risiko usahatani kubis pada lahan kering dan lahan sawah tadah hujan di Kecamatan Gisting Kabupaten Tanggamus. Jurnal Ilmu Ilmu Agribisnis, 3 (1): $2-8$ http://jurnal.fp.unila.ic.id/index.php/JIA/articl e/viewFile/1011/916 [30 Oktober 2018].

Darseno. 2013. Budidaya Lele. PT Agromedia Pustaka. Jakarta.

Dinas Kelautan dan Perikanan Provinsi Lampung. 2019. Produksi Ikan Lele Menurut Kabupaten/Kota di Provinsi Lampung tahun 2014-2018. Dinas Kelautan dan Perikanan Provinsi Lampung. Bandar Lampung.

Dinas Peternakan dan Perikanan Kabupaten Lampung Tengah. 2019. Statistik Peternakan dan Perikanan 2019. Pemerintah Kabupaten Lampung Tengah. Gunung Sugih.

Direktorat Jenderal Perikanan Budidaya. 2019. Produksi Perikanan Budidaya Kolam Menurut Jenis Ikan Provinsi Lampung. Direktorat Jenderal Perikanan Budidaya. Jakarta.
Heriani N, Zakaria WA, dan Soelaiman A. 2013. Analisis keuntungan dan risiko usahatani tomat di Kecamatan Sumberejo Kabupaten Tanggamus. Jurnal Ilmu Ilmu Agribisnis, 1 (2): 170-177. http:// jurnal.fp.unila.ic.id/index.php/JIA/article/view /244/243. [30 Oktober 2018].

Kadarsan HW. 1995. Keuangan Pertanian dan Pembiayaan Perusahaan Agribisnis. Gramedia Pustaka Utama. Jakarta.

Soekartawi. 1995. Analisis Usahatani. PT Raja Grafindo Persada. Jakarta.

Soekartawi, Rusmiadi, dan E Damaijati. 1993. Risiko dan Ketidakpastian Dalam Agribisnis/Teori dan Aplikasi. Raja Grafindo Persada. Jakarta.

Sugiarto D, S Sunaryanto, dan DS Oetomo. 2003. Teknik Sampling. Gramedia Pustaka Utama. Jakarta.

Saputra I, Lestari DAH, dan Nugraha A. 2017. Analisis efisiensi produksi dan perilaku petani dalam menghadapi risiko pada usahatni jagung di Kecamatan Natar Kabupaten Lampung Selatan. Jurnal Ilmu Ilmu $\begin{array}{llll}\text { Agribisnis, } & 6 & \text { (2): } & \text { 117-124. }\end{array}$ http://jurnal.fp.unila.ac.id/index. php/JIA/article/view/2776.2322. November 2019]. 